\title{
Cross-Cultural Adaptation and Evidence of Validity of the Questionnaire d'Engagement Paternel
}

\author{
Carina Nunes Bossardi1, *, Carolina Duarte de Souza ${ }^{2}$, Lauren Beltrão Gomes ${ }^{3}$, \\ Simone Dill Azeredo Bolze ${ }^{2}$, Beatriz Schmidt ${ }^{4}$, Mauro Luis Vieira ${ }^{2}$, \\ Daniel Paquette ${ }^{5}$ \& Maria Aparecida Crepaldi ${ }^{2}$ \\ ${ }^{1}$ Universidade do Vale do Itajaí, Itajaí, SC, Brasil \\ ${ }^{2}$ Universidade Federal de Santa Catarina, Florianópolis, SC, Brasil \\ ${ }^{3}$ Fundação Universidade Regional de Blumenau, Blumenau, SC, Brasil \\ ${ }^{4}$ Universidade Federal do Rio Grade do Sul, Porto Alegre, RS, Brasil \\ ${ }^{5}$ Université de Montréal, Montréal, QC, Canada
}

\begin{abstract}
This study aimed to investigate the internal structure and reliability indices of the Questionnaire d'Engagement Paternel (QEP). It describes the process of cross-cultural adaptation and results of the evaluation of the psychometric proprieties of the instrument. The sample consisted of 300 participants (150 mothers and 150 fathers), who formed two-parent families. The psychometric analyses involved procedures including back translation, factor analysis, and reliability analyses of the instrument. The Brazilian version of the QEP is presented, containing a total of 36 items, divided into five dimensions. Twenty items were excluded, according to statistical and theoretical criteria. The results demonstrated satisfactory evidence of validity of the scale. Considerations regarding limitations of the study and recommendations for use in future research were indicated.
\end{abstract}

KEYWORDS: test validity, paternity, fathers, involvement, parental involvement, measurement

\section{Adaptação Transcultural e Evidências de Validade do Questionário de Engajamento Paterno}

\begin{abstract}
RESUMO - Este estudo teve como objetivo investigar a estrutura interna e os índices de confiabilidade do Questionário de Engajamento Paterno (QEP). Propõe-se descrever o processo de adaptação transcultural e os resultados da avaliação das propriedades psicométricas do instrumento. A amostra foi composta por 300 participantes (150 mães e 150 pais), que formavam famílias biparentais. Nas análises psicométricas, foram seguidos procedimentos envolvendo back translation, análise fatorial e análise da confiabilidade do instrumento. Apresenta-se a versão brasileira do QEP, contendo o total de 36 itens, divididos em cinco dimensões. Houve exclusão de 20 itens, conforme critérios estatísticos e teóricos. Os resultados demonstraram evidências satisfatórias de validade e precisão da escala. Considerações sobre limitações do estudo e indicações de uso para pesquisas futuras foram apontadas.
\end{abstract}

PALAVRAS-CHAVE: validade do teste, paternidade, pais, envolvimento, envolvimento parental, medidas

Changes in the configurations and dynamics of families, leveraged by social and economic transformations in the industrialized countries, have redefined the attributions and responsibilities of each of the parents (Shwalb, Shwalb, \&. Lamb, 2013; Vieira et al., 2014; Zvara, Schoppe-Sullivan, \& Dush, 2013). This has contributed to the emergence of new expectations and beliefs about the behaviors of mothers and fathers in the family context, and about how they are to care for their children (Fagan, Day, Lamb, \& Cabrera, 2014). In this regard, recent studies have characterized the paternal functions in the family and in child development, suggesting an increase in paternal involvement, with the more active

*E-mail: carinabossard@yahoo.com.br 
participation of the father in the care of the child (Bossardi, Gomes, Crepaldi, \& Vieira, 2013; Fagan et al., 2014; Zvara et al., 2013, Vieira et al., 2014).

Paternal involvement has been a subject of interest to researchers, due to its diversity between various cultures and to the transformations it has undergone over time as a result of contextual, historical and economical changes in each society (Shwalb et al., 2013), as well as to the evidence of its relationship with human development (Newland, Coyl-Shepherd, \& Paquette, 2012; Vieira et al., 2014). High levels of paternal involvement in care for children are related to lower levels of problems in childhood (Cabrera, Cook, McFadden, \& Bradley, 2012), particularly with regard to the modulation of child aggression (Gomes, Crepaldi, \& Bigras, 2013). The development of socio-emotional skills also has a positive relationship with high levels of paternal involvement (Anderson, Roggman, Innocenti, \& Cook, 2013; Cabrera et al., 2012), above all relating to the substitution of physical aggression for verbal negotiation strategies in preschool children (Gomes et al., 2013).

In conceptual terms, there are various ways of defining paternal involvement. A significant number of studies on paternal involvement has been based mainly in the conceptual structure developed by Lamb, Pleck, Charnov and Levine (1985), which define it as behaviors and activities undertaken by the father for the sake of his/her child. These authors consider the phenomenon to be made up of three dimensions: interaction, accessibility and responsibility. Interaction, or engagement, is defined as the direct contact of the father with the child in care and shared activities; accessibility refers to the presence and availability of the father in the sense of making himself accessible to the child, allowing interactions to occur; and responsibility is the role that the father exercises, ensuring care and resources for the child, such as hiring a babysitter, arranging appointments with pediatricians, or purchasing clothes and foods. In this way, as shown above, the more the father undertakes these activities, the greater tends to be his involvement with the child (Shwalb et al., 2013), considered a protective factor for child development (Newland et al., 2012; Vieira et al., 2014).

There is a consensus among researchers that paternal involvement is multidimensional, that is, it is made up of different dimensions (Palkovitz, 1997; Schoppe-Sullivan, McBride, \& Ringo Ho, 2004); however, there are various proposals regarding what these dimensions are (Day \& Lamb, 2004; Dubeau, Devault, \& Paquette, 2009; Palkovitz 1997; Pleck, 2010; Schoppe-Sullivan et al., 2004). Palkovitz (1997) argued for the tri-dimensionality proposed by Lamb et al. (1985), but proposed a model with 15 subdimensions, whereas Day and Lamb (2004) included in the model of Lamb et al. (1985) behavioral, affective and cognitive practices of the father with regard to the child. Schoppe-Sullivan et al. (2004) proposed a model with four dimensions: responsibilities, affection/ communication, participation in activities and cognitive monitoring. Dubeau et al. (2009) adopts the term paternal engagement ${ }^{1}$ and defined it as the continuous participation and concern of the father, whether biological or substitute, regarding the development and physical and psychological well-being of his child, expressed in different ways: (a) Father in interaction: the presence of the father with regard to the child, whether direct or indirect; (b) Father who cares: who shares routine tasks; (c) Affectionate father: who provides gestures and words that reassure and encourage the child; (d) Responsible father: who undertakes tasks for the development of the child; (e) Providing father: who provides financial support for the child's needs; and (f) Evocative/ significant father: a father who thinks about or remembers the child when he/she is not with him.

This diversity of models of paternal involvement is reflected in the existence of the various definitions, instruments and ways of accessing the phenomenon (Dubeau et al., 2009; Schoppe-Sullivan et al., 2004). In the light of the importance of paternal involvement for child development, emphasis is placed on the need to use validated and reliable instruments to measure this. Its measuring is important for the undertaking of studies to identify the reality of paternal involvement, studies that might support the planning of public policies which encourage the involvement of the father with a view to promoting child development.

In one literature review, Gomes, Bossardi, Cruz, Crepaldi and Vieira (2014) investigated the description of the psychometric properties of the instruments used for measuring paternal involvement. To this end, they analyzed 15 Brazilian and international studies published between 2000 and 2012. The results revealed an increase in the number of studies on paternal involvement over time, with seven studies being published in 2010 and 2011. In 13 of the 15 studies analyzed, it was possible to identify the variety of instruments used to measure paternal involvement, as well as their representation in international studies in comparison with studies published in Brazil (represented in only two studies). Attention was called to the shortage of information regarding the psychometric qualities of measuring instruments and the ones validated for the Brazilian context. Cronbach's alpha was the rate used most in the studies analyzed. These results indicate, according to the authors, the need to construct and/or adapt and validate instruments appropriate for the Brazilian scenario (Gomes et al., 2014).

According to Cross-Cultural Psychology, it is essential to use instruments which show evidence of validity to deal with the topic in Brazil, containing theoretical dimensions of paternal involvement that respect the cultural differences (Berry, Poortinga, Breugelmans, Chasiotis, \& Sam, 2011). Adapted versions of measuring instruments may promote

1 Free translation of the French engagement paternel. 
advances in research and knowledge about the phenomenon studied as well as - in some cases - allowing the undertaking of cross-cultural studies (Borsa, Damásio, \& Bandeira, 2012), which could provide data for more efficient strategies for improving human development (Hambleton \& Patsula, 1998). The adaptation of questionnaires for different cultures and languages often involves lack of care on the part of the researchers regarding the psychometric properties of the items or of the questionnaire itself, principally in relation to reliability (consistency or quality of measuring without errors) and validity (congruence with the qualities of the objects being measured), which may impair the quality of the results produced (Pilatti, Pedroso, \& Gutierrez, 2010).

Authors who have analyzed studies on cross-cultural adaptations of instruments note that few of these focus on or describe the scientific rigor required in this type of study (Egisdóttir, Gerstein, \& Çinarbas, 2008). As a result, some concentrate only on the translation of the instrument (Borsa \& Bandeira, 2014) and few have invested in an in-depth process regarding equivalents of the procedures adopted in studies involving different cultures. Accordingly, we highlight the importance of presenting more detailed information and recommendations to the researchers, so that the validity of the studies' results may be guaranteed (Egisdóttir et al., 2008).

In this regard, the present study aims to investigate the internal structure and the reliability indices of the Questionnaire d'Engagement Paternel (QEP). This instrument was developed and validated in Canada, with a sample of 468 two-parent families, with at least one child aged between zero and six years old (Paquette, Bolté, Turcotte, Dubeau, \& Bouchard, 2000). Factorial analysis indicated the existence of six dimensions, explaining $42.2 \%$ of the variance in the data, with Cronbach's alpha between 0.72 and 0.86 ; and one-month temporal stability of 33 participants between 0.50 and 0.77 , indicating that not all the data may be considered satisfactory.
The six dimensions are: (a) Emotional Support (variance explained $=10.7 ; \alpha=0.86 ; r=0.72$ ) referring to gestures and words which reassure and encourage the child; (b) Openness to the World (variance explained $=7.0 ; \alpha=0.75 ; \mathrm{r}=0.77$ ), relates to encouraging the child to go further and explore his/her surroundings; (c) Basic Care (variance explained = $6.4 ; \alpha=0.73 ; r=0.50)$, relates to providing essential care for survival, such as feeding, clothing and bathing; (d) Physical Play (variance explained $=6.4 ; \alpha=0.72 ; \mathrm{r}=0.75$ ), relates to interacting with the child physically through gestures and play; (e) Evocations (variance explained $=6.0 ; \alpha=0.74 ; \mathrm{r}=$ 0.61 ), relates to thinking about, remembering and/speaking of the child; (f) Discipline (variance explained $=5.7 ; \alpha=$ $0.75 ; \mathrm{r}=0.74)$, relates to actions controlling behaviors, i.e., the act of correcting and reprimanding the child (Paquette et al., 2000). Later, the authors included an additional dimension: Household Chores $^{2}$, covering domestic activities in general, such as shopping, preparing meals, cleaning and making necessary repairs.

Although the QEP instrument was originally developed to assess paternal engagement, since its creation it has also been applied to mothers, in its original version in two-parent families, with a view to assessing parental involvement and to assessing the involvement of the father in comparison with the involvement of the mother (Dubeau et al., 2009; Paquette et al., 2000). There is a tendency in this area to use instruments originally developed to assess fathers' involvement to evaluate the involvement of mothers (Pleck \& Hofferth, 2008; Prof \& Wild, 2017), including the broadening of constructs previously limited to paternal involvement so as also to include the maternal figure, such as the recognized model proposed by Lamb et al. (1985; Lang et al., 2014; Prof \& Wild, 2017). In this vein, in the present study, as in the assessment of the evidence of the validity of the original QEP, the decision was made to include the mothers in the sample.

\section{METHOD}

This is a study of evidence for the validity of an instrument and, therefore, is characterized as descriptive observational, cross-sectional and exploratory, taking into account the factorial and relational analyses of the QEP's psychometric properties. The instrument proposed was used in a research project undertaken through a partnership between a Brazilian university and two Canadian universities, entitled The intergenerational transmission of

2 This dimension was included by the authors after the study of the evidence for the QEP's validity. There is, therefore, no information about the Cronbach's alpha or temporal stability violence: The relationship between marital and parental conflict and aggressivity among pairs of children aged from 4 to 6 years old. In this project, parental involvement was treated as an important variable for understanding the marital and parental family relationships. As a result, the researchers sought to characterize the maternal and paternal involvements in care for the children. The process of the QEP's cross-cultural adaptation comprised four stages, and the study of its psychometric properties involved a further two procedures, producing a total of six stages. 


\section{Participants}

One professor with a Ph.D. in Psychology, proficient in French and with experience of using the language abroad, participated in Stage 1. A doctoral student in Psychology also proficient in French, and with experience of using the language abroad - participated in Stage 2. The checking of the semantic similarities and discrepancies between these two versions was undertaken by four graduate students in Psychology, undertaking Master's or doctoral degrees, members of the research group of which the larger project was a part, with instrumental sufficiency in French. For Stage 3 , a committee of specialists was formed, made up of three judges - professionals who are experts in the instrument's area of interest. In Stage 4, the instrument was applied to eight participants (five mothers and three fathers).

In Stages 5 and 6, 150 heterosexual couples $(n=$ 300 ) with at least one child between four and six years old participated. This was, therefore, a non-probabilistic convenience sample, given that the contact with the participating families took place through Child Education Institutions in four cities in the Southern region of Brazil. As inclusion criteria, the couples had to have been living together for at least six months and to be aged 18 years old or over at the time of the birth of the child who was the focus of the study.

The mean age of the mothers was 33 years old $(\mathrm{SD}=$ $6.30)$, and that of the fathers was 36 years old ( $\mathrm{SD}=7.70)$. The mean educational level of the mothers was 12 years $(\mathrm{SD}=4.19)$ and that of the fathers, 11 years $(\mathrm{SD}=4.38)$. The declared family income varied between $\mathrm{R} \$ 600.00$ and R \$ 11,500.00 per month. Regarding the child's age, 59 were aged between 4 years old and 4 years and 11 months, 70 were aged between 5 years old and 5 years and 11 months, and 21 were aged between 6 years old and 6 years and 11 months.

\section{Instrument}

The QEP is originally made up of 56 items distributed in seven dimensions: Emotional Support (12 items); Openness to the World (9 items); Basic Care (9 items); Physical Play (7 items); Evocations (6 items); Discipline (4 items); and Household Chores (9 items). This instrument uses two scales to assess the frequency with which the parents undertake specified activities with their children. In this regard, the first 24 questions of the original instrument have a six-point ascending scale involving relative frequency, with the descriptors never, once a month, two or three times a month, once a week, various times a week and every day. The other questions must be answered by the parents using a five-point Likert-type response scale with the following descriptors never, sometimes, often, nearly always and always. Hence, the higher the score, the greater the parental involvement.
In its version adapted to the Brazilian context, it presented Cronbach's alpha of 0.78 for the mother and 0.89 for the father, evidencing its reliability (Bossardi, 2015). Regarding reliability, these rates are considered appropriate (Pasquali, 2010; Sampieri, Colado, \& Lucio, 2013).

\section{Procedures}

The project was approved by the Ethics Committee for Research Involving Human Beings, of the Federal University of Santa Catarina under Decision number 520/2009.

Prior to being administered, the instrument went through a process of cross-cultural adaptation so that evidence of its validity could later be assessed. To this end, procedures were undertaken to assess semantic, conceptual, cultural, idiomatic, operational and measurement-related equivalency as suggested by Pasquali (2010) and Sampieri et al. (2013). The adaptation involved theoretical procedures, such as definition of the construct, translation and back translation of the instrument, analysis by the judges (professionals who specialize in the area of the phenomenon being studied) and semantic analysis (equivalents of the meanings, suitability of the expressions, taking into account the construct and the target-population of the study) (Pasquali, 2010).

Below, we present the procedures undertaken according to the stages of the adaptation process and evidence of validity (Figure 1). In Stage 1, the professor with a Ph.D. in Psychology undertook the translation process. Stage 2 involved the back translation of the instrument by the doctoral student in Psychology, proficient in French. After these two initial stages, and before beginning the later stage, the material produced was analyzed and checked by four graduate students of Psychology. The students' participation was undertaken to provide comparison and checking of the translated version with the back translation, with the aim of contributing as reviewers, preparing the version of the instrument to be handed to the external judges. Stage 3 involved the evaluation of the semantic, conceptual, cultural and idiomatic equivalencies by the experts in the instrument's area of interest. Finally, in Stage 4, the evaluation of operational equivalence and face validity of the items was undertaken through the application of the instrument to eight participants (five mothers and three fathers).

After the necessary changes, referent to Stages 1 and 2 , a pilot study was undertaken in a room with a one-way mirror, and the instruments were administered by two researchers to a group of volunteer participants. The other researchers involved in the project watched the application from behind the mirror and made notes for later discussion. This procedure relates specifically to Stages 3 and 4, corresponding to the semantic, conceptual, cultural, and idiomatic equivalencies, and to the pilot study, or operational 

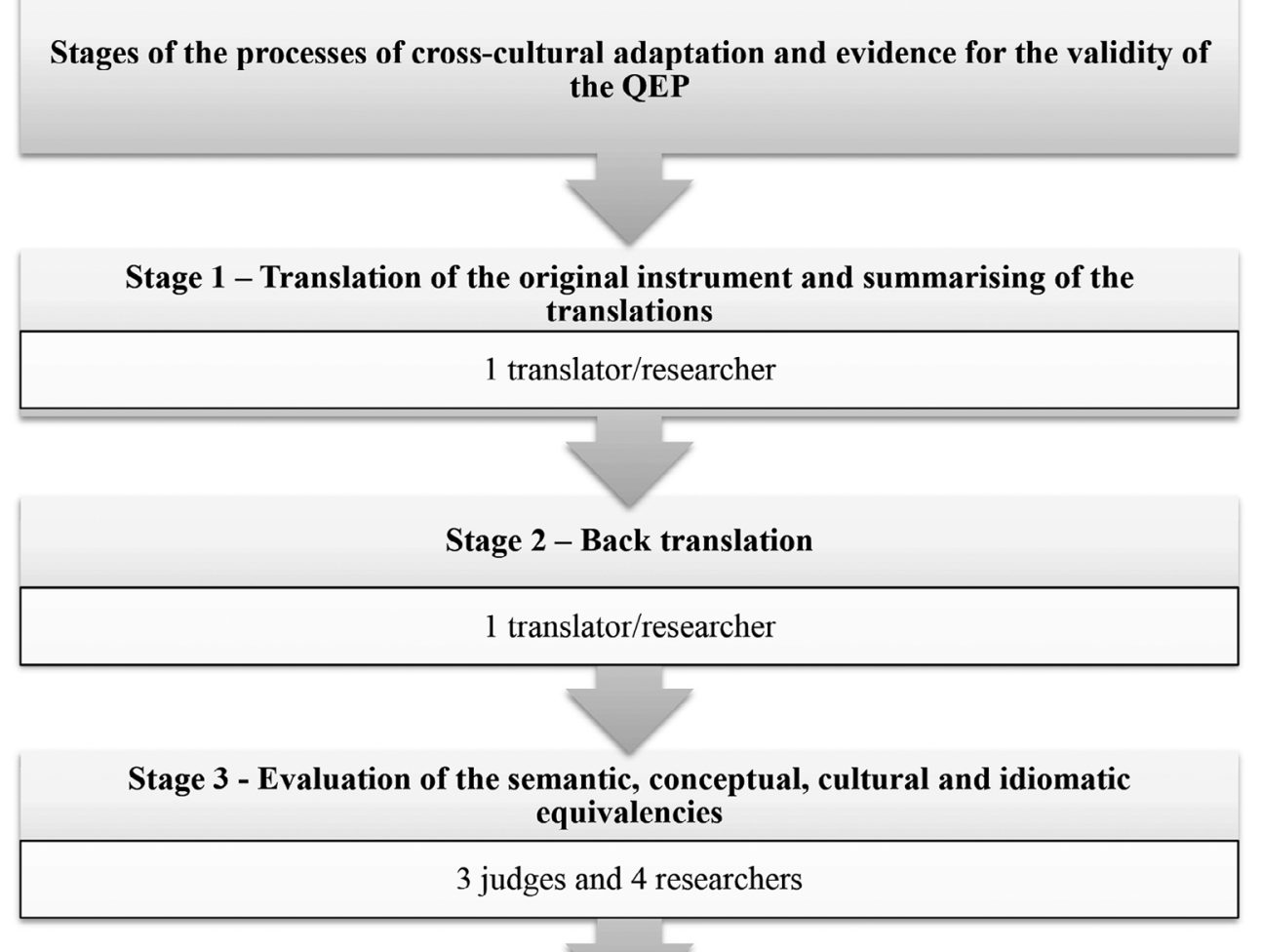

Stage 4 - Evaluation of the operational equivalence and face validity of the items

\begin{tabular}{|c|}
\hline 8 participants ( 5 mothers and 3 fathers) \\
\hline Stage 5 - Evaluation of the evidence for the validity of the construct \\
\hline 300 participants (150 fathers and 150 mothers with at least one child between 4 and 6 \\
years old)
\end{tabular}

Figure 1. Flowchart of the stages of the cross-cultural adaptation of the Questionnaire d'Engagement Paternel.

equivalents and face validity of the items. This procedure's aim was to assess the suitability of the translated instrument to the context of research, as well as serving as training for the interviewers, in the sense of standardizing the interview process and the application of the instruments. The questions highlighted by the volunteers as raising doubts or difficult to interpret during the application of the instrument were discussed by the researchers.

For evaluating the evidence for validity relating to the internal structure and reliability of the instrument, the data were collected between 2009 and 2011. In this period, approximately 400 families were approached, via Child Education Institutions from four cities in the South region of Brazil; only 150 accepted to participate. All those who met the study's inclusion criteria and who accepted to participate signed the Consent Form. The questionnaire was answered by the mothers and fathers separately, in their homes, and was administered by one of the researchers.

Stage 5 addressed the process of evidence for the validity of the construct, which went through empirical 
(the administration of the questionnaire) and analytical procedures (appropriate statistical analyses; Pasquali, 2010; Sampieri et al., 2013). Stage 6 included the evaluation of accuracy and reliability. Accordingly, Stages 5 and 6 referred to assessment of the evidence for validity relating to internal structure and reliability of the instrument.

\section{Data Analysis}

For the process of cross-cultural adaptation, referent to Stages 1, 2, 3 and 4, the research team, along with the judges, made the relevant adaptations in a qualitative way, in line with the procedures indicated in the literature for this process (Pasquali, 2010; Sampieri et al., 2013). These analyses have also been undertaken in other studies with this purpose (Bolsoni-Silva \& Loureiro, 2016; Gomes \& Boruchovitch, 2016).

Regarding the analysis of the psychometric properties, covered in Stages 5 and 6, concerning the evidence for construct validity and assessment of accuracy and reliability, in order to assess the factorability of the items, the researchers used the Kaiser-Meyer-Olkin (KMO) and Bartlett's Test of Sphericity indicators. Following that, an Exploratory Factorial Analysis involving principal axis factoring was undertaken, given that this method does not require the multivariate normality of the data, and the application of the VARIMAX rotation, as this prioritizes the simple structure in the loading of the items (Laros, 2004). The minimum factor loading criteria of 0.40 was stipulated for the inclusion of the items, a value that has been the minimum recommended in the literature (Pasquali, 2010; Sampieri et al., 2013).

Reliability analysis was undertaken using Cronbach's alpha and Guttman's Lambda-2. After the final adjustments, the VARIMAX rotation was undertaken again, including the Lambda-2 tests, the alpha (containing information on the global alpha and on the alpha if the item was deleted) in each dimension and, furthermore, the correlation of each item with the total instrument, to adjust according to the reliability of the instrument and of the dimensions (Pasquali, 2010; Sampieri et al., 2013).

\section{RESULTS}

The cross-cultural adaptation of the QEP comprises modifications performed in accordance with each stage. In the process of translation and back translation, the researchers sought to maintain verisimilitude with the original version of the instrument; accordingly, substitutions of words were not yet undertaken in this initial process. Substitution of some words and expressions, necessary in line with the meaning and cultural context, was undertaken after the analysis performed as much by the judges as by the participants in the pilot study. In accordance with the analyses made during Stages 3 and 4, some words had to be substituted with semantic equivalents - or examples of actions were added to the questions, with the aim of minimizing difficulties in understanding. Alterations were suggested by the judges regarding the translation and the meaning of some expressions for the Brazilian population. As an example of the changes made, one can refer to item 14, whose literal translation in Portuguese would be cuidar dos cabelos de seu filho (caring for your child's hair) but which was changed to cuidar dos cabelos de seu filho (lavar, pentear) [caring for your child's hair (washing, combing)]. In these stages involving cross-cultural adaptation, all the questions were discussed by the researchers with the judges, for the later standardization of the instruments' items.

In the analysis of the empirical evidence for validation, it was observed that it was necessary to undertake a process of reducing the number of factors by one (from seven to six, six to five, and so on). Some items presented a complex factor loading. As a result, the procedures for the final adaptations of the items were followed so that these would remain in one or another dimension. The theoretical background was the criteria used predominantly for assessing the suitability of each item/factor.

The scree plot, represented by Figure 2, showed structures of three, five and six factors as appropriate configurations. Likewise, the authors chose to extract five factors due to theoretical adequacy, reasonable levels of self-values and percentage of explained total variance $(47.11 \%)$. The factorability of the data matrix was considered appropriate for undertaking the factorial analysis using Bartlett's test of sphericity $\left(\chi^{2}=3482.19 ; \mathrm{gl}=630 ; \mathrm{p}<0.001\right)$ and according to the Kaiser-Meyer-Olkin (KMO) index, with a value of 0.87 (Pasquali, 2010; Sampieri et al., 2013).

According to Table 1, the components presented a factor loading above 0.50 in factors 1 (Direct and Indirect Care) and 3 (Evocations). In factor 2 (Emotional Support), the factor loading ranged between 0.69 and 0.45 . Factor 4 (Physical Play and Openness to the World) presented a loading of 0.65 to 0.45 . In factor 5 (Discipline), the factor loading ranged between 0.76 and 0.46 .

Due to theoretical decisions and the factor loading of the items, 20 items were removed from the original instrument $(11,25,40,41,56,44,22,49,16,52,39$, 20, 34, 32, 23, 36, 30, 26, 31 and 27). For this, item 43, Punishing your son/daughter when he/she does something wrong (hurting somebody, etc.) obtained a factor loading of 0.42 in the dimension of Emotional Support, and 0.36 in the dimension of Discipline; nevertheless, for theoretical 


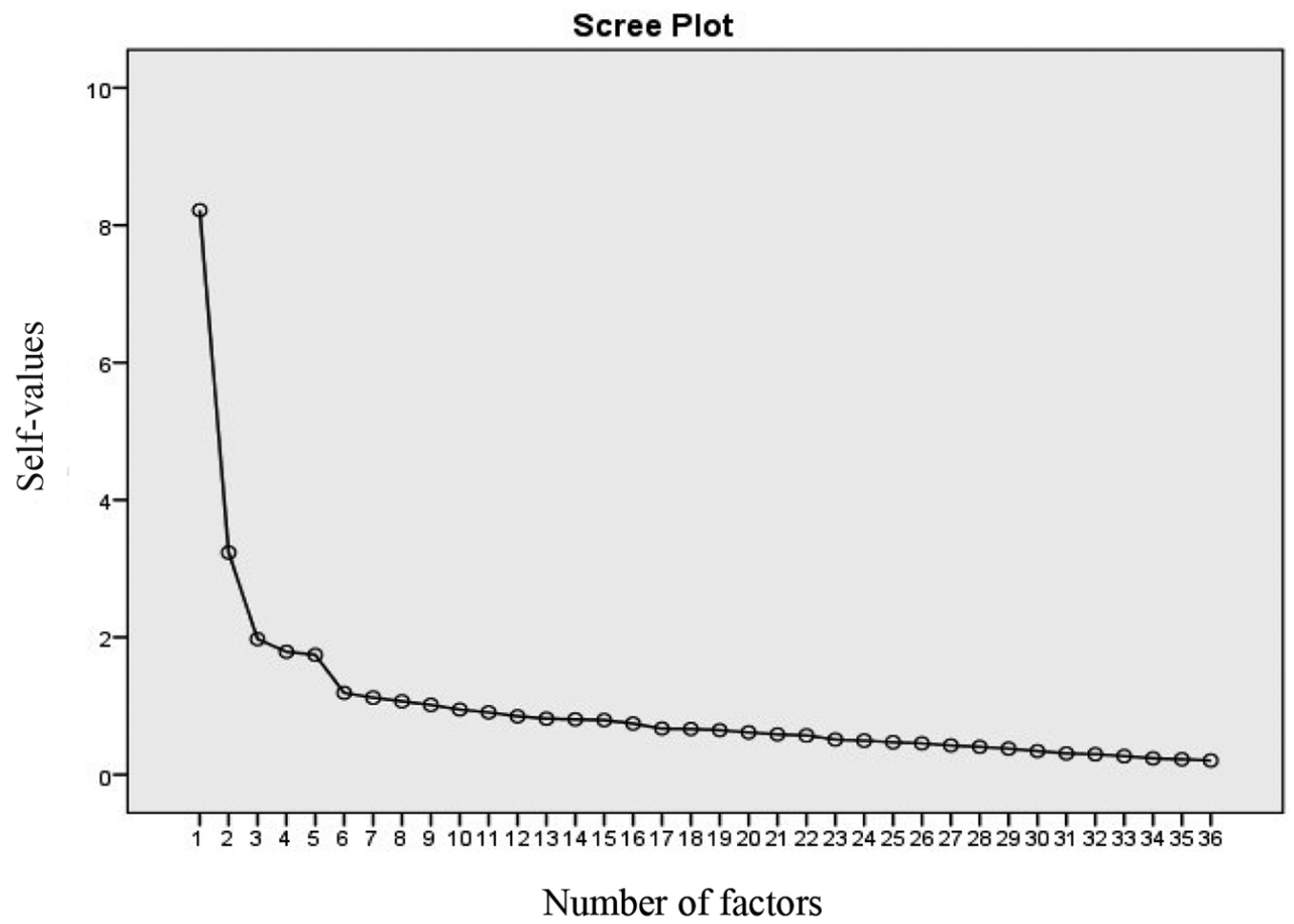

Figure 2. Scree Plot Test for the number of factors of the QEP.

reasons, the decision was made to keep it in its original dimension. In this proposal, the factors of Basic Care and Household Chores were shown to be unidimensional, as were Physical Play and Openness to the World. The factors of Emotional Support, Evocations and Discipline were kept. Furthermore, the decision to adapt or exclude items followed the results obtained by the Cronbach's alpha and the item total correlation, as indicated in Table 2 .

At the end, the questionnaire's internal consistency, as measured using the Lambda-2, was 0.88 - and the Cronbach's alpha was 0.87 . These values were considered acceptable, and ranged from 0.59 to 0.91 for the Lambda-2 and from 0.55 to 0.90 for the alpha among the instrument's factors. It is possible to note that, after the procedures established in the construct validity, the removal of the items did not result in an increase of the Cronbach's alpha for the dimension, with the exception of the dimension of Discipline, in which the exclusion of item 18 contributed to raising the alpha from 0.55 to 0.57 . The researchers decided to keep the item in accordance with the theoretical criteria adopted.

Regarding the item-total correlation, it was observed that Direct and Indirect Care and Emotional Support presented coefficients of approximately 0.45 or above. The same was not the case in other dimensions. In Evocations, item 38 presented a coefficient below 0.40. In Physical Play,
Openness to the World and Discipline, nearly all of the indices were below 0.40 , i.e., with levels below the others, given that they also presented alpha and Lambda-2 results that were low when compared with the other factors, thus indicating the need for the description of the indices and of the theoretical analysis.

After the procedures undertaken to evidence the validity of the content and construct and the analysis of reliability, the final version of the QEP was presented, containing a total of 36 items, divided into five dimensions. The factors of the Brazilian version of the instrument are as follows: (a) Direct and Indirect Care (11 items: 1, 2, 4, 5, 7, 9, 10, $12,14,21,28)$ - providing care essential for survival, such as feeding, dressing and bathing, as well as caring for activities related to the home in general, that is, shopping, preparing meals, cleaning and making necessary repairs; (b) Emotional Support (10 items: 35, 37, 42, 45, 46, 47, 48, 50, $53,55)$ - making gestures and saying words which reassure and encourage the child; (c) Evocations (5 items: 17, 29, 38, $51,54)$ - thinking about, remembering and/or speaking about the child; (d) Physical Play and Openness to the World (6 items: $3,6,8,13,15,33)$ - encouraging the child to explore the environment and go further, as well as interacting with him/her physically through gestures and play; (e) Discipline (4 items: 18, 19, 24, 43): managing the child's behavior, i.e., acts correcting and reprimanding the child. 
Table 1. Explanatory factorial analysis with VARIMAX rotation of the items of the QEP

\begin{tabular}{|c|c|c|c|c|c|}
\hline \multirow{2}{*}{ Items } & \multicolumn{5}{|c|}{ Factors } \\
\hline & 1 & 2 & 3 & 4 & 5 \\
\hline QEP4 Washing the dishes & 0.78 & & & & \\
\hline QEP14 Caring for your child's hair & 0.77 & & & & \\
\hline QEP9 Washing clothes & 0.74 & & & & \\
\hline QEP7 Dressing your child & 0.74 & & & & \\
\hline QEP21 Cleaning the house & 0.73 & & & & \\
\hline QEP5 Giving your child a bath & 0.71 & & & & \\
\hline QEP1 Preparing meals & 0.70 & & & & \\
\hline QEP12 Supervising morning routines & 0.63 & & & & \\
\hline QEP2 Giving your child something to eat or drink & 0.60 & & & & \\
\hline QEP28 Cleaning your child's ears & 0.59 & & & & \\
\hline QEP10 Putting your child to bed at night & 0.53 & & & & \\
\hline QEP53 Encouraging your child & & 0.69 & & & \\
\hline QEP47 Congratulating the child & & 0.67 & & & \\
\hline QEP46 Trying to find out from your child if something is wrong with him/her & & 0.61 & & & \\
\hline QEP37 Reassuring your child when he/she is scared & & 0.61 & & & \\
\hline QEP50 Soothing your child & & 0.60 & & & \\
\hline QEP48 Consoling your child when he/she cries & & 0.52 & & & \\
\hline QEP45 Proposing educational play & & 0.52 & & & \\
\hline QEP35 Caring for your child when he/she is sick & & 0.49 & & & \\
\hline $\begin{array}{l}\text { QEP55 Intervening quickly when your child gives signs of difficulty or } \\
\text { discomfort }\end{array}$ & & 0.49 & & & \\
\hline QEP42 Giving your child first aid when he/she is hurt & & 0.45 & & & \\
\hline $\begin{array}{l}\text { QEP29 Speaking about your child to your friends, neighbors or work } \\
\text { colleagues }\end{array}$ & & & 0.74 & & \\
\hline $\begin{array}{l}\text { QEP17 Telling your work colleagues or friends funny things that your child } \\
\text { has said or done }\end{array}$ & & & 0.68 & & \\
\hline QEP51Looking at photos of your child & & & 0.60 & & \\
\hline QEP54 Remembering your child when he/she was younger & & & 0.59 & & \\
\hline QEP38 Thinking about your child when he/she is not with you & & & 0.50 & & \\
\hline QEP13 Playing with your child on your back & & & & 0.65 & \\
\hline QEP6 Tickling your child & & & & 0.62 & \\
\hline QEP8 Watching a children's television program with your child & & & & 0.52 & \\
\hline QEP15 Making your child laugh & & & & 0.51 & \\
\hline QEP3 Playing rough and tumble play with the child & & & & 0.51 & \\
\hline $\begin{array}{l}\text { QEP33 Teaching your child sports (swimming, skating, riding a bicycle, } \\
\text { throwing a ball, etc.) }\end{array}$ & & & & 0.45 & \\
\hline QEP24 Reprimanding your child when he/she disobeys & & & & & 0.76 \\
\hline QEP19 Reprimanding your child when he/she disturbs or annoys people & & & & & 0.68 \\
\hline QEP18 Correcting your child's behavior at the table & & & & & 0.57 \\
\hline $\begin{array}{l}\text { QEP43 Punishing your child when he/she does something wrong } \\
\text { (hurting somebody, etc.) }\end{array}$ & & & & & 0.46 \\
\hline$\%$ of variance explained by the factor & 22.83 & 8.98 & 5.48 & 4.97 & 4.85 \\
\hline$\%$ of total variance accumulated & 22.83 & 31.81 & 37.29 & 42.26 & 47.11 \\
\hline
\end{tabular}


Table 2. Analyses of the internal consistency and correlational analyses of the factors and items of the instrument

\begin{tabular}{|c|c|c|c|}
\hline Items/dimension & $\begin{array}{l}\text { Alpha if the item } \\
\text { is deleted }\end{array}$ & Item-total & $\begin{array}{l}\text { Alpha; Lambda-2 } \\
\text { of the dimension }\end{array}$ \\
\hline \multicolumn{4}{|l|}{ Direct and Indirect Care (11 items) } \\
\hline 1. Preparing meals & 0.89 & 0.64 & \\
\hline 2. Giving your child something to eat or drink & 0.89 & 0.54 & \\
\hline 4. Washing the dishes & 0.89 & .0 .68 & \\
\hline 5. Giving your child a bath & 0.89 & 0.66 & \\
\hline 7. Dressing your child & 0.89 & .0 .69 & $0.90 ; 0.91$ \\
\hline 9. Washing clothes & 0.89 & 0.67 & \\
\hline 10. Putting your child to bed at night & 0.90 & 0.46 & \\
\hline 12. Supervising the morning routine (breakfast, getting dressed) & 0.89 & 0.61 & \\
\hline 14. Caring for your child's hair (washing, combing) & 0.88 & 0.75 & \\
\hline 21. Cleaning the house (sweeping, cleaning the floor, dusting) & 0.89 & 0.67 & \\
\hline 28. Cleaning your child's ears & 0.89 & 0.62 & \\
\hline \multicolumn{4}{|l|}{ Emotional Support (10 items) } \\
\hline 35. Caring for your child when he/she is sick & 0.80 & 0.53 & \\
\hline 37. Reassuring your child when he/she is scared & 0.80 & 0.51 & \\
\hline 42. Giving your child first aid when he/she is hurt & 0.81 & 0.44 & \\
\hline 45. Proposing educational play for your child & 0.81 & 0.48 & \\
\hline 46. Trying to find out from your child if something is wrong with him/her & 0.79 & 0.59 & $0.81 ; 0.80$ \\
\hline 47. Congratulating your child when he/she manages to achieve something & 0.80 & 0.53 & \\
\hline 48. Consoling your child when he/she cries & 0.81 & 0.41 & \\
\hline 50. Reassuring your child & 0.79 & 0.59 & \\
\hline 53. Encouraging your child when he/she manages to do something difficult & 0.80 & 0.54 & \\
\hline 55. Intervening quickly when your child gives signs of difficulty or discomfort & 0.80 & 0.48 & \\
\hline \multicolumn{4}{|l|}{ Evocations (05 items) } \\
\hline $\begin{array}{l}\text { 17. Telling your work colleagues or friends funny things that your child has } \\
\text { said or done }\end{array}$ & 0.60 & 0.52 & \\
\hline 29. Speaking about your child to your friends, neighbors or work colleagues & 0.56 & 0.60 & \\
\hline 38. Thinking about your child when he/she is not with you & 0.69 & 0.32 & $0.69 ; 0.73$ \\
\hline 51. Looking at photos of your child & 0.65 & 0.42 & \\
\hline 54. Remembering your child when he/she was younger & 0.65 & 0.40 & \\
\hline \multicolumn{4}{|l|}{ Physical Play and Openness to the World (06 items) } \\
\hline 3. Playing rough and tumble play with your child & 0.56 & 0.26 & \\
\hline 6. Tickling your child & 0.50 & 0.38 & \\
\hline 8. Watching a children's television program with him/her & 0.53 & 0.32 & \\
\hline 13. Playing with your child on your back (pony ride) & 0.51 & 0.35 & $0.57 ; 0.61$ \\
\hline 15. Making your child laugh & 0.54 & 0.36 & \\
\hline $\begin{array}{l}\text { 33. Teaching your child sports (swimming, skating, riding a bicycle, throwing } \\
\text { a ball, etc.) }\end{array}$ & 0.53 & 0.31 & \\
\hline \multicolumn{4}{|l|}{ Discipline (04 items) } \\
\hline 18. Correcting your child's behavior at the table & 0.57 & 0.22 & \\
\hline 19. Reprimanding your child when he/she disturbs or annoys people & 0.34 & 0.49 & \\
\hline 24. Reprimanding your child when he/she disobeys & 0.51 & 0.30 & $0.55 ; 0.59$ \\
\hline $\begin{array}{l}\text { 43. Punishing your child when he/she does something wrong (hurting } \\
\text { somebody, etc.) }\end{array}$ & 0.46 & 0.35 & \\
\hline
\end{tabular}




\section{DISCUSSION}

The present study aimed to investigate the internal structure and indices of reliability of the QEP, with a view to fostering its use in the Brazilian context. This is an important contribution, in the light of the multidimensionality and the multi-determination of the construct of parental involvement, as well as the relevance of studies examining the paternal role in child development from a cross-cultural perspective, based on evidence of similarities and differences between different contexts (Berry et al., 2011; Dubeau et al., 2009).

The analysis of the psychometric properties of the instrument revealed the existence of five factors, rather than seven, confirming, in the same way, the multidimensionality of the phenomenon presented. Furthermore, among the main findings of this study, it was possible to identify similarities and also differences in the comparison made between the original version and the adapted Brazilian version. Of the 56 items and seven dimensions, after the adaptation process, the instrument came to have 36 items distributed in five dimensions - which were later characterized in five factors in accordance with the original dimensions, as well as a result of the theoretical analysis and the factor loading of the items.

As shown in the analyses, in the Brazilian version, the instrument presented better evidence after the exclusion of the 20 items and the re-grouping of the dimensionality into five factors. The following factors were kept: Emotional Support; Evocations and Discipline. Basic Care and Household Chores, on the other hand, were represented by a single dimension titled Direct and Indirect Care. The same occurred with Physical Play and Openness to the World, which were grouped, bearing in mind the factor loadings and the exclusion of the items. No factor, therefore, was suppressed - rather, they were grouped and reorganized based on the evidence for validity.

Regarding the reorganization of the seven factors to five, and their identification in the respective dimensions, the researchers followed the theoretical procedures which were concomitant with the empirical indications. The characterization of Direct and Indirect Care was owed to the fact that these two types of parental involvement were established, given that among the factors, emphasis is placed on activities referent to direct involvement, that is, those covering actions undertaken in the presence of the child, such as bathing, feeding and caring for him/her - and to indirect involvement, corresponding to those activities undertaken for the sake of the child, without the child necessarily being present - represented by responsibilities for the home, domestic tasks and providing financial resources. It is believed that this understanding provides general and specific information regarding involvement and interaction with the children (Bossardi, 2015; Dubeau et al., 2009).

Likewise, the grouping of the factors Physical Play and Openness to the World was justified by the fact that studies undertaken on paternal engagement have indicated some specific issues in the interaction of the father with sons or daughters. These findings suggest that Physical Play and Openness to the World are complementary and are linked more to the paternal function in care for children. In Activation Relationship Theory (Paquette, 2004), it is proposed that the father tends to interact with the child through contact, during fun activities or physical play that try to challenge the child emotionally and cognitively, so as to promote openness to the world. In promoting openness to the world, the father puts the child in situations in which the child is obliged to confront the environment around him/her, while the father provides protection and imposes limits - that is, the father tends to encourage the child to run risks while ensuring safety, allowing him/her to develop courage in unfamiliar situations (Newland et al., 2012; Paquette, 2004).

The decision to exclude items was undertaken due to the unsatisfactory evidence for the item's inclusion in any one of the factors, which was confirmed after the theoretical analysis of the meaning of each item and also of the item for the total construct. In this regard, the following items are highlighted as examples: 25 - Accompanying your child to the houses of friends, relatives or neighbors; 27 - Going to the park with your child and 30 - Occupying oneself with car repairs. These items may not have presented a satisfactory factor loading due to a cultural difference between the characteristics of cities in the South of Brazil and cities in the province of Québec.

From the literature, it is possible to infer that models of parental systems, beliefs and practices originating from one specific culture may have specific characteristics due to the cultural context in which they are found. Therefore, such analyses are justified and need to be considered in later studies (Berry et al., 2011; Egisdóttir et al., 2008). The evidence obtained through the present study made it possible to identify and discuss similarities and differences between the instrument, in its original version and the version adapted to the Brazilian context. It is possible that not all of the practices recognized culturally as part of parental involvement in Canada will be considered parental practices in Brazil, or, furthermore, that differences exist in the dimensions comprising paternal involvement between the Canadian and Brazilian populations, which could support the differences found in the empirical structure of the measure for Brazil. 


\section{FINAL CONSIDERATIONS}

The present study contributed through the proposal of evidence for validity for the adapted version of the QEP. This being the case, the factors of the adapted version of the QEP allow one to identify different forms of engagement: Emotional Support, Direct and Indirect Care, Evocations, Physical Play and Openness to the World, and Discipline. In this regard, it contributes through the knowledge concerning paternal involvement, which may be broadened to parental involvement, and relating to issues specific to mothers and fathers, based on the individual and contextual differences; and may also show the mother's influence on the father's involvement. The results of the present study suggest the viability of the use of the QEP instrument in Brazil. Studies of this nature could contribute to understanding and analyzing parental engagement in general.

It is necessary to highlight the indices with reasonable evidence, thus causing a need for evaluation and investigation of gaps between the evidence proposed and adopted by this study. To this end, further investigations are suggested seeking to improve understanding of the dimensions of Physical Play and Openness to the World and Discipline, whose indices could be improved. Thus, it is indicated that we should seek to extend knowledge regarding the factors, as well as to broaden the number of items and the size of the sample.

It is important to emphasize that the way in which the items of the dimension of Discipline are written may have contributed to these limitations, as the items indicate coercive behaviors such as punishment, reprimanding and correction. In this case, it is indicated that one should use terms indicating more limits, such as explanation of rules, among others. Moreover, the dimension of Evocations (whose items presented factor loadings above 0.50 , alpha of 0.69 and Lambda-2 of 0.73) also need revision of the items, bearing in mind their importance, principally for parents who - for whatever reason - do not live together or do not have direct contact with the children every day.

It is also suggested that it is necessary to assess the evidence for validity with a greater number of participants, based on a sample calculation that allows the generalization of the data. It is necessary to include quantitative indices for assessing the procedure of cultural adaptation (such as the CVC, ICC and Kappa, among others). Emphasis is also placed on the relevance of extending the level of investigation for the various family configurations which have been outlined, in both the Brazilian and international scenarios, and, in the same way, to expand the data to cover the cultural diversity of Brazil, by including other states, through undertaking multicentric studies.

In consonance with the indications aiming for results more favorable to the evidence for the factors of Physical Play and Openness to the World and Discipline, the Questionnaire d'Overture au Monde (QOM), also developed in Canada, and currently being adapted for the Brazilian population, is recommended for future studies. This instrument was created based on the Activation Relationship Theory, mentioned above, and relates to some specific paternal functions, which could be of interest for shedding light on these phenomena. Furthermore, it is suggested that quantitative and qualitative measures for assessing engagement should be developed, adapted and validated, having the construct and dimensions discussed here as a basis. These could be useful for assessing the phenomena in studies conducted in Brazil.

3 Free translation: Openness to the World Questionnaire.

\section{REFERENCES}

Anderson, S., Roggman, L. A., Innocenti, M. S., \& Cook, G. A. (2013). Dads' parenting interactions with children: Checklist of observations linked to outcomes (PICCOLO-D). Infant Mental Health Journal, 34(4), 339-351.

Berry, J.W., Poortinga, Y. H., Breugelmans, M. S., Chasiotis, A., \& Sam, D. L. (2011). Cross-cultural psychology: Research and applications ( $3^{\mathrm{a}}$ ed.). Cambridge: Cambridge University Press.

Bolsoni-Silva, A. T., \& Loureiro, S. R. (2016). Validação do questionário de avaliação de habilidades sociais, comportamentos, contextos para universitários. Psicologia: Teoria e Pesquisa, 32(2), 1-10.

Borsa, J. C., \& Bandeira, D. R. (2014). Adaptação transcultural do questionário de comportamentos agressivos e reativos entre pares no Brasil. Psico-USF, 19(2), 287-296.

Borsa, J. C., Damásio, B. F., \& Bandeira, D. R. (2012). Adaptação e validação de instrumentos psicológicos entre culturas: Algumas considerações. Paidéia, 22(53), 423-432.
Bossardi, C. N. (2015). Envolvimento e interações paternas com filhos de 4 a 6 anos: Relações com os sistemas parental e conjugal (Tese de doutorado). Universidade Federal de Santa Catarina, Florianópolis, SC, Brasil. Retrieved from https:// repositorio.ufsc.br/handle/123456789/135279

Bossardi, C. N., Gomes, L. B., Crepaldi, M. A., \& Vieira, M. L. (2013). Engajamento paterno no cuidado a crianças de 4 a 6 anos. Psicologia Argumento, 31(73), 237-246.

Cabrera, N. J., Cook, G. A., McFadden, K. E., \& Bradley, R. H. (2012). Father residence and father-child relationship quality: Peer relationships and externalizing behavioral problems. Family Science, 2(2), 109-119.

Day, R., \& Lamb, M.E. (2004). Conceptualizing and measuring father involvement. Mahwah, NJ: Erlbaum.

Dubeau, D., Devault, A., \& Paquette, D. (2009). L'engagement paternel, un concept aux multiples facettes. In D. Dubeau, A. Devault, \& G. Forget (Eds.), La paternité au XXI sièle (pp. 71-98). Québec, Canada: Les Presses de l’Université Laval. 
Egisdóttir, S., Gerstein, L. H., \& Çinarbas, D. C. (2008). Methodological issues in cross-cultural counseling research: Equivalence, bias, and translations. The Counseling Psychologist, 36(2), 188-219.

Fagan, J., Day, R., Lamb, M. E., \& Cabrera, N. J. (2014). Should researchers conceptualize differently the dimensions of parenting for fathers and mothers? Journal of Family Theory \& Review, 6(4), 390-405.

Gomes, L. B., Crepaldi, M. A., \& Bigras, M. (2013). O engajamento paterno como fator de regulação da agressividade em préescolares. Paidéia, 23(54), 21-29.

Gomes, L. B., Bossardi, C. N., Cruz, R. M., Crepaldi, M. A., \& Vieira, M. L. (2014). Propriedades psicométricas de instrumentos de avaliação do envolvimento paterno: Revisão de literatura. Avaliação Psicológica, 13(1), 19-27.

Gomes, M. A. M, \& Boruchovitch, E. (2016). Escala de motivação para a leitura para adolescentes e jovens: Propriedades psicométricas. Psicologia: Teoria e Pesquisa, 32(2), 1-9.

Hambleton, R. K., \& Patsula, L. (1998). Adapting tests for use in multiple languages and cultures. Social Indicators Research, 45(1-3), 153-171.

Lamb, M. E., Pleck, J. H., Charnov, E. L., \& Levine, J. A. (1985). Paternal behavior in humans. American Zoologist, 25(3), 883-894.

Lang, A. N., Schoppe-Sullivan, S. J., Kotila, L. E., Feng, X., Dush, C. M. K., \& Johnson, S. C. (2014). Relations between fathers' and mothers' infant engagement patterns in dual-earner families and toddler competence. Journal of Family Issues, 35(8), $1107-1127$.

Laros, J. A. (2004). O uso da análise fatorial: Algumas diretrizes para pesquisadores. In L. Pasquali (Ed.), Análise fatorial para pesquisadores (pp. 163-193). Petrópolis: Vozes.

Newland, L. A., Coyl-Shepherd, D. D., \& Paquette, D. (2012). Implications of mothering and fathering for children's development. Early Child Development and Care, 183(3-4), 337-342.

Palkovitz, R. (1997). Reconstructing "involvement": Expanding conceptualizations of men's caring in contemporary families. In A.J. Hawkins \& D.C. Dollahite (Eds.), Generative fathering. Beyond deficit perspectives (pp. 200 - 216). Thousand Oaks, CA: Sage.

Paquette, D. (2004). Theorizing the father-child relationship: Mechanisms and developmental outcomes. Human Development, 47(4), 193-219.
Paquette, D., Bolté, C.,Turcottea, G., Dubeau, D., \& Bouchard, C. (2000). A new typology of fathering: Defining and associated variables. Infant and Child Development, 9(4), 213-230.

Pasquali, L. (2010). Instrumentação psicológica: Fundamentos e práticas. Porto Alegre: Artmed.

Pilatti, L. A., Pedroso B., \& Gutierrez G. L. (2010). Propriedades psicométricas de instrumentos de avaliação: Um debate necessário. Revista Brasileira de Ensino de Ciência e Tecnologia, 3(1), 81-91.

Pleck, J. H. (2010). Paternal involvement: Revised conceptualization and theoretical linkages with child outcomes. In M. E. Lamb (Ed.), The role of the father in child development (pp. 58-93). Hoboken, NJ: Wiley.

Pleck, J. H., \& Hofferth, S. L. (2008). Mother involvement as a influence on father involvement with early adolescents. Fathering, 6(3), 267-286.

Prof, W., \& Wild, L. G. (2017). Mother, father and grandparent involvement: Associations with adolescents' mental health and substance use. Journal of Family Issues, 38(6), 776-797.

Sampieri, R. H., Colado, C. F., \& Lucio, P. B. (2013). Metodologia de pesquisa. São Paulo: McGraw Hill.

Schoppe-Sullivan, S. J., McBride, B. A., \& Ringo Ho, M. H. (2004). Unidimensional versus multidimensional perspectives on the father involvement. Fathering, 2(2), 147-163.

Shwalb, D. W., Shwalb, B. J., \& Lamb, M. E. (2013). Final thoughts, comparisons, and conclusions. In D. W. Shwalb, B. J. Shwalb \& M. E. Lamb (Eds.), Fathers in cultural context (pp. 385-399). New York; London: Psychology Press.

Vieira, M. L., Bossardi, C. N., Gomes, L. B., Bolze, S. D. A., Crepaldi, M. A., \& Piccinini, C. A. (2014). Paternidade no Brasil: Revisão sistemática de artigos empíricos. Arquivos Brasileiros de Psicologia, 66(2), 36-52.

Zvara, B. J., Schoppe-Sullivan, S. J., \& Dush, C. K. (2013). Fathers' involvement in child health care: Associations with prenatal involvement, parents' beliefs, and maternal gatekeeping. Family Relations, 62(4), 649-661.

Submitted: 06/08/2017

Reviewed: 30/01/2018

Accepted: 13/03/2018 